
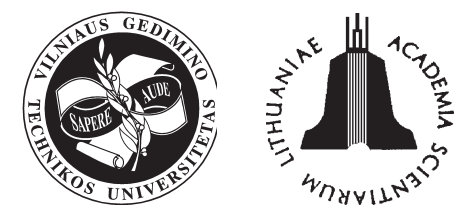

ISSN 1648-4142 TRANSPORT

www.transport.vtu.lt

\title{
ROAD SAFETY AUDIT - POSSIBILITY TO AVOID A DANGEROUS ROAD SECTION
}

\author{
Alvydas Pikūnas, Vidmantas Pumputis \\ Dept of Automobile Transport, Vilnius Gediminas Technical University, J. Basanavičiaus g. 28, LT-03224 Vilnius, \\ Lithuania.E-mail: tiauto@ti.vtu.lt
}

Received 7 March 2005; accepted 25 June 2005

\begin{abstract}
The number of road traffic casualties is still very high, even though the number of fatalities in European countries is falling. In road traffic accidents involving personal injury, economic resources are destroyed and the productivity of economy is correspondingly impaired. Costs resulting from traffic accidents represent the largest single part of the overall cost of traffic in economus. Knowledge about the harm it does to economy is essential if measures to reduce road traffic accidents are identified and introduced. Economic evaluation of road safety measures using cost-benefit analysis is based on the costs incurred as a result of road accidents. The avoidance of such costs represents the economic benefit of road safety measures. Road safety audit is a formal procedure for independent assessment of the accident potential and likely safety performance of a specific design for a road or traffic scheme - either new construction or alteration of an existing road.
\end{abstract}

Keywords: road safety, audit, traffic environment, benefits and costs.

\section{Introduction}

Each year the global figures of the people perished in automobile traffic accidents reach 700000 next to 15-20 million of the injured ones. In other words, more than 1100 people are killed in the world every day and more than 40000 become injured [1]. Rapid growth of automobilisation causes an increasing number of problems in the efforts to ensure safe traffic on the Lithuanian roads and streets. Ensuring safe traffic is one of the most urgent traffic problems. About 122000 traffic accidents were registered in Lithuania from 1982 to 2004 during which 18216 people were killed and about 130500 injured. In 2004, 749 persons were killed on the Lithuanian roads and streets. In Lithuania annual losses caused by road traffic accidents amount to approximately 1,3 billion LTL [2]. Once the economic assessment of road safety measures has been made, the work of improving safety in accordance with economic criteria can be organized as efficiently as possible. To this end, it is necessary to select measures that are likely to be successful, to quantify their effects and lastly to evaluate them. The object is to employ available resources in such a way as to achieve the greatest possible benefit for society. Even with a favourable trend in the incidence of road accidents there is still a need for measures to increase road safety. Such measures can be introduced at different stages of an accident scenario. But there is one purpose for road safety measures to create safe road environment. The first step is a planning process.

\section{Steps of a traffic planning process}

Traffic planning includes activities in order to set up programs and plans for effective transport service under consideration of economic, social and environmental factors. Traffic planning is highly integrated with land use planning both on a comprehensive regional level and on a detailed local level [3]. Examples of traffic planning projects are:

- Structure plans - for regions and larger urban areas including policy formulation, general proposals for distribution of population, land use pattern, location of activities and a need for transportation and communication systems.

- Transportation plans - proposals for successive development of transport systems and networks for the movement of people and goods integrated with land use planning, economic development, environmental and energy saving programs.

- Area plans - design of traffic networks for new development of specific areas for housing, industries, service, recreation and for the renewal of existing areas.

- Traffic management - traffic regulation and flow control for making an existing transport system more efficient under consideration of safety and environmental factors. 
Generally, the traffic planning process covers the following steps (Fig 1):

a) Inventory of existing traffic conditions including surveys of traffic flow and transport demand, analysis of accident situation, environmental impact;

b) Prediction of future conditions including general studies of economic growth, demographic and land use changes, traffic growth;

c) Formulation of goals and objectives for transportation service in connection with policy making procedure;

d) Problem formulation based on steps (a)-(c);

e) Preparation of alternative proposals in order to find out relevant solutions to the problem;

f) Traffic assignment for each of the alternatives in order to forecast traffic demand including trip generation, modal split and network assignment;

g) Evaluation of consequences for each of the alternatives including impact studies, cost-benefit analysis;

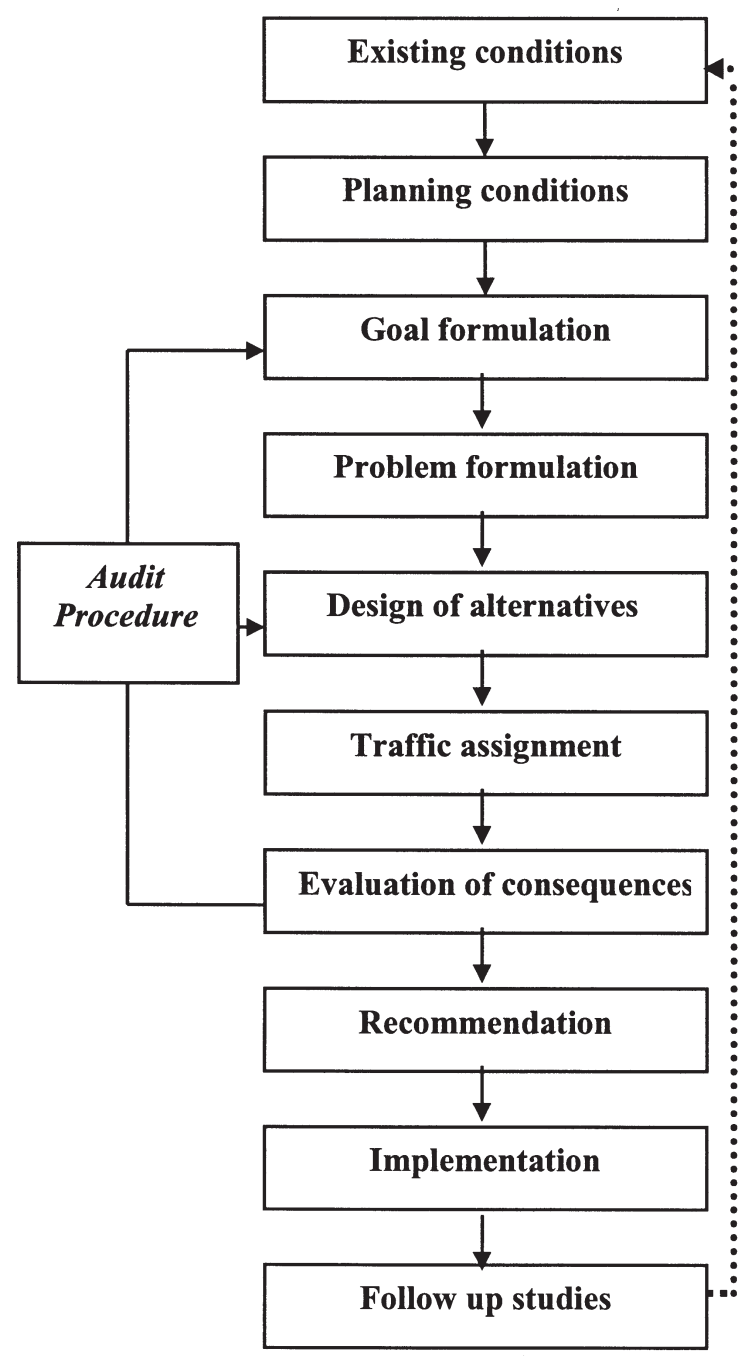

Fig 1. Steps of a traffic planning process h) Recommendation including design standards, step-by-step implementation, financing;

i) Follow-up studies and research including the analysis of obtained results (before-after studies) and the development of planning models and methods.

The process includes political decisions and public participation. Detailed road safety audit procedure is presented in part 4.

\section{Planning of road safety measures}

In traffic planning traffic safety issues play an important role and in many cases the reduction of accidents will be an essential objective in policy making and problem formulation. The consideration of traffic safety in a planning and design process implies also positive effects on other sectors such as economy, environment protection and energy saving.

Through foresighted traffic planning the frequency and severity of accidents can be reduced on the drawing-desk and many lives can be saved. It is also important to point out that traffic planners and engineers must be aware and also make decision makers and other professionals aware that the planning stage involves possibilities which have a more permanent influence on traffic safety for decades: It is better at the initial planning step to adapt the traffic environment to road users, than later on to adapt road users to a badly designed environment [4] (Fig 2).

Planning of road safety measures is a complex exercise, since a great many such measures - technical and non-technical - are available [5]:

- The potential of technical measures to improve road safety has yet to be exhausted. In recent years technical innovations have led to a steady increase of road safety (e.g. airbag, strengthened passenger compartment, plastic fuel tank). But active and passive safety can be improved still further in future through technical means (e.g. telematics applications).

Active security can be increased by the improvement of human behaviour. Education and training programmes for those using roads can help reduce individual traffic problems.

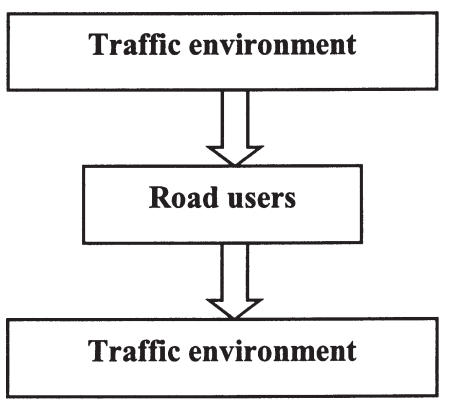

Fig 2. Relation between a road user and traffic environment 
Even in the context of the economic framework conditions there are possibilities for increasing road safety. By the way, for example, changes of insurance tariffs can provide incentives for prudent behaviour on the roads.

Economic evaluation of road safety measures using cost-benefit analysis is based on the costs incurred as a result of road accidents [6]. The avoidance of such costs represents the economic benefit of road safety measures. If the scale of these benefits is to be ascertained, the costs of road accidents must be worked out. The costs of safety measures cover implementation and upkeep. The ratio of benefits to costs represents the economic advantage of safety measures:

Cost-benefit ratio $=$ benefit $/$ costs $=$ reduction of accident costs / costs of measures

According to more widely held interpretation the benefits of the measure encompass other reductions in costs, such as those resulting from emissions, noise or loss of time. It should be born in mind that road safety measures can also produce higher costs which are offset by the overall benefits (e.g. loss of time due to speed limits).

\section{Road safety audit - the examination of an existing or future road}

Road safety audit must be the formal examination of an existing or future road or traffic project in which an independent, qualified team reports on the project's accident potential and safety performance. There are clear, positive benefits from a road safety audit process. One study revealed a first year rate of return of $146 \%$ - a wonderful return in any language. And the cost of an audit is low (in the order of 0,2$0,5 \%$ of the total project cost: the higher the total project cost, be lower this percentage drops). With such low costs and high returns road safety audit is a process that should appeal to all levels of governments in all countries.

The new edition of the Austroads road safety audit guide outlines the six stages of audit [7]:

1. Feasibility stage audits.

By providing a specific safety input at the feasibility stage of a scheme, road safety audit can influence fundamental issues such as route choice, standards, impact on and continuity with the existing adjacent network, and intersection or interchange provision.

2. Preliminary design stage audits.

This audit occurs on completion of the preliminary road design. Typical considerations will include horizontal and vertical alignments and intersection layouts. Subsequent significant changes in road alignment become much harder to achieve after this stage as land acquisition and other associated legal matters become finalized.

3. Detailed design stage audits.

This audit occurs on completion of the detailed road design, but before the preparation of contract documents. Typical considerations include geometric layout, linemarkings, signals, lighting, signing, intersection details, clearances to roadside objects (crash barriers/frangibility) and provision for vulnerable road users. Attention to detail at this design stage can do much to reduce the costs and disturbances associated with last minute changes which may otherwise be brought about with a pre-opening audit. It is cheaper and easier to change some marks on a drawing than later to re-build or rectify a road project that proves to be hazardous.

4. Pre-opening stage audits.

This audit involves detailed inspection of a new scheme prior to its opening. The new road is driven, ridden and walked upon (when appropriate) by the audit team to ensure that the safety needs of all road users are provided for. Nighttime inspection is particularly important to check signage, delineation and other darkness-related issues.

5. Safety reviews of existing roads.

This audit aims to ensure that the safety features of a road are compatible with the functional classification of the road and to identify any feature which may develop over time into a safety concern. Regular audits of existing roads allow road safety hazards to be identified before they result in accidents.

6. Roadwork audits.

This involves audits of both the traffic management plans for use during the roadwork phase of a road project and the roadwork site itself. This second part involves the inspections (day and night) of the site to examine safety issues such as signs, roadside protection and traffic management during each phase of the project.

\section{Benefits and costs of road safety audit}

The Austroads study has completed an international review of recent literature finding four studies which demonstrate the benefits of road safety audit [8]:

- A study in Great Britain that compared before and after crash statistics for a sample of audited schemes and non-audited schemes found that audited schemes achieved an average casualty saving per year of 1,25 , compared to a saving of 0,26 for non-audited schemes.

- Another study in Great Britain found that the 
average saving from implementing changes at the design stage rather than after the project was constructed was approximately USD 15,000 [6].

- An evaluation study which involved a cost benefit analysis of 13 projects in Denmark that had been subject to road safety audit gave a first year rate of return of $146 \%$.

A study in the Middle East which considered a number of projects that were not subject to road safety audit, but developed problems soon after construction concluded that road safety audit would have provided a first year rate of return of $120 \%$.

\section{Road safety activity on the Lithuanian roads}

At the present moment there is no road safety auditing system in Lithuania. In general improving road safety situation in Lithuania cost benefits analysis and treatment of „,black spots” are implemented. According to the methodology presented by the Kaunas Transport and Road Research Institute the socioeconomic cost per fatalities is about 300000 Euro. In Lithuania performed detailed analysis of accidents and high-accident locations ("black spots") determines the punctual accident causes and helps to select measures to reduce the number of accidents. Since 1994 the Transport and Road Research Institute carried out the analysis of the "black spots" and high-accident locations on the main and national Lithuanian roads. For high-accident locations the analysis of accident causes is made and proposals to reduce the accident rate are made leading economic evaluation of traffic safety measures is carried out [9].

A road section is defined as a black spot if in the period of 4 years the actual number of accidents on the section is higher than the minimum number and the accident rate coefficient (AK) is higher than 0.5 (motorways and I class roads) or 0,8 (II-V class roads):

$$
\begin{aligned}
& A_{\text {fact }}>A_{\text {min }}, \\
& A K>0,5 \text { or }>0,8,
\end{aligned}
$$

here:

$\mathrm{A}_{\text {fact }}$ is the actual number of accidents that have occurred on the road section in the period of 4 years;

$\mathrm{A}_{\min }$ is the minimum number of accidents that might have occurred on the road section in the period of 4 years.

Let us assume that the minimum number of accidents $\mathrm{A}_{\min }=3$.

The choice of the assumption $\mathrm{AK}>0,5$ is based on previous experience.

The requirement $A_{\text {fact }}>A_{\min }$ has been included so that road sections are not to be defined as black spots if they have very few accidents occurring on them ( 1 or 2 accidents in four years).
To establish the level of accident rate there are the following parameters used: accident density (AT) and an accident rate coefficient (AK). An accident rate coefficient correlates with the annual number of accidents per 1 million vehicles passing the road section:

$$
\mathrm{AK}=\mathrm{A} 10^{6} / 365 \mathrm{NLm},
$$

here:

A is the number of accidents in the black spot in four years;

$\mathrm{N}$ is the mean value calculated of the annual traffic volume per day; veh./day;

$\mathrm{L}$ is the length of the black spot, $\mathrm{km}$; $m$ is the number of years $(m=4)$.

Accident density (AT) is a parameter reflecting the number of accidents per kilometre per year:

$\mathrm{AT}=\mathrm{A} / \mathrm{Lm}$.

Black spots are generally established with the help of a stretch. A stretch is a constant and equals $1=500 \mathrm{~m}$.

After the list of black spots is amended, the accident density AT is calculated.

In the list the black spots are prioritized. The list should start with the black spots with the highest accident density.

\section{Steps for the implementation of road safety audit in Lithuania}

In Lithuania we are suggesting to put road safety audit into new jurisdiction. It follows the "top down" approach and, while other approaches can and do the work, experience has shown that achieving commitment of the process at the highest level at the earliest time is the most successful and cost-effective way to start this process.

1. Write road safety audit explicitly into the national road safety strategy.

During the consultation period for the development of the road safety strategy leaders need to be made aware of the road safety audit process, its benefits and its costs. Explicit recognition of road safety audit in a national road safety strategy is the starting point for all following actions.

2. Put a national road safety audit policy into the national road safety plan.

Such a policy may be brief and it should cover issues such as:

- the type of road projects which are to be audited and the stages of audit;

- the road safety audit procedure to be followed;

- the reporting system within the audit process;

- the responding system within the audit process. 


\section{Develop an agreed road safety audit proce- dure}

By adopting a road safety audit procedure and by applying it within the design department of national, provincial/state and local road authorities, road safety audit can start at minimum cost and with minimum disruption to existing programs.

The procedure should detail matters such as:

- who may be in the audit team;

- the presentation style of the audit report;

- where the audit reports are sent;

- who is to respond to the audit report findings;

- who is to have final arbitration authority in the event of a dispute.

4. Adopt a set of road safety audit guidelines.

Such guidelines provide a focus for road safety audit and thereby assist with the widespread awareness and understanding of the audit process within the profession. In time these guidelines become an integral part of the program for road safety audit workshops.

5. Maximize awareness of the road safety audit process

Relatively few road safety professionals have attended any formal workshop on road safety audit. To ensure that the road safety an audit process takes hold in a uniform manner and to establish a process which is recognized as formal and worthwhile it is usually necessary to hold a number of road safety audit awareness/training workshops. The initial workshop should be held in conjunction with the launch of the new policy on road safety audit and it should be repeated as often as required.

There are three groups of professionals in need of specific information about the road safety audit process:

- those who need awareness of the process in order to make it happen in new jurisdiction (typically department heads, road safety professionals and senior managers);

- those practitioners who are to do the audits (typically engineers, designers, police, behaviourists and other road safety professionals);

- those who are to use the audit reports and respond to the audit outcomes (typically project managers and design managers).

6. Develop a national system for monitoring progress with road safety audit.

This should include activities such as recording of the number of audits and the stage of audits, identifying common safety concerns arising from these audits, and establishing the level of compliance with the process. It should include recording of the numbers of individuals undertaking training workshops and participating in audits to assist with the accredi- tation system for auditors. The quality of responses from the designers and Project Managers, the overall outcomes of the process including its benefits and its costs and the need for amendments to the procedures are other issues to monitor.

\section{Conclusions}

At the present moment there is no road safety auditing system in Lithuania. In general all the work of improving road safety situation in Lithuania is the implementation of cost benefits analysis and the treatment of ,black spots”. In Lithuania we are suggesting:

1. To integrate road safety audit into new jurisdiction.

2. To write road safety audit explicitly into the national road safety strategy.

3. To put national road safety audit policy into the national road safety plan.

4. To develop an agreed road safety audit procedure.

5. To adopt a set of road safety audit guidelines.

6. To maximize the awareness of the road safety audit process.

7. To develop a national system for monitoring progress with road safety audit.

\section{References}

1. White paper, European transport policy for 2010: time to decide" 2001.

2. Lithuanian National Road Safety Programme for the period 2005-2010 approved by the Government of Lithuania.

3. Gunnarsson O. Urban and Traffic Planning with Respect to Traffic Safety VTI/BATS international conference, 1996 SAE Technical paper, No SAE-9707, p 38-41;

4. OECD. Behavior adaptation to changes in road transport system. Road Research. Paris, 1990.

5. Jordan, P. W. Road Safety Audit - a Partnership for Traffic Safety. 1996 ITE Journal, March.

6. Belcher, M. and Proctor, S. The Use of Road Safety Audit in Great Britain. 1993 Febuary Traffic Engineering and Control, p. 61-65.

7. Pieplies, T. R. Road Test of the Road Safety Audit Process. ITE Journal, January, 1999.

8. ECMT Road Safety Policy in Lithuania - National Peer Revue, Paris, 2004.

9. Chapuis, J. L. Socio-economic cost of road accidents; Final report of action COST 313. Commission of the European Communities, Directorate-General XIII, Brussels. 